

\title{
Commodity Tax Competition with Constrained Taxes
}

Pascal Belan, Stéphane Gauthier

\section{To cite this version:}

Pascal Belan, Stéphane Gauthier. Commodity Tax Competition with Constrained Taxes. Journal of Public Economic Theory, 2009, 11 (4), pp.653-665. 10.1111/j.1467-9779.2009.01424.x . hal-00731318

\section{HAL Id: hal-00731318 https://hal.science/hal-00731318}

Submitted on 13 Sep 2012

HAL is a multi-disciplinary open access archive for the deposit and dissemination of scientific research documents, whether they are published or not. The documents may come from teaching and research institutions in France or abroad, or from public or private research centers.
L'archive ouverte pluridisciplinaire HAL, est destinée au dépôt et à la diffusion de documents scientifiques de niveau recherche, publiés ou non, émanant des établissements d'enseignement et de recherche français ou étrangers, des laboratoires publics ou privés. 


\title{
Commodity tax competition with Constrained Taxes
}

\author{
Pascal Belan * Stéphane Gauthier ${ }^{\dagger}$
}

6th August 2008

\begin{abstract}
This paper examines symmetric Nash equilibria of a two-country model of fiscal competition with a continuum of taxable commodities in each country. The innovation is to impose a uniformity restriction that there can be only two rates of tax on the different commodities, a positive rate and the zero-rate. The main results characterize, under two alternative modes of taxation, the equilibrium fiscal rules chosen by countries, i.e., the level of the positive rate and the set of taxed commodities. Under the origin principle, it appears that the equilibrium fiscal base is narrower than the optimal one, and consequently the tax rate is too high. By contrast, under the destination principle, the optimal rule is implemented.
\end{abstract}

Key words: fiscal competition, origin and destination principles, number of available tax rates.

JEL classification number: H7.

${ }^{*}$ LEN, Université de Nantes.

$\dagger$ ENSAE and CREST-LMA.

$¥$ Corresponding author: Stéphane Gauthier, ENSAE, 3 avenue Pierre Larousse, 92245 Malakoff cedex, France; Phone number: +33141176535; Fax number: +33141173852; E-mail address: gauthier@ensae.fr. 


\section{Introduction}

The literature on non-cooperative tax setting usually assumes that different goods can be taxed at different rates (Mintz and Tulkens, 1986; Kanbur and Keen, 1993). In the European Union, however, the VAT harmonization policy imposes strong restrictions on the number of VAT rates that can be used. According to the 2006/112/EC Directive 'on the common system of value added tax', goods subject to VAT typically must be taxed at one single standard (high) rate. In addition, Member States are allowed to apply one or two reduced (low) rates to a few goods specified in a restricted list. As a rough approximation, therefore, the EU legislation imposes the uniformity restriction that there can be only two VAT rates on the different goods, a positive rate and the zero-rate. The innovation of this paper is to analyze commodity tax competition in the presence of such a uniformity restriction.

This restriction implies that each country has to choose not only the level of its own tax rate, but also its own tax base, i.e., the set of goods taxed at the positive rate. Both decisions closely rely on the mode of competition under scrutiny. We consider two alternative modes of competition. The first one is the 'destination principle', by which goods are taxed at the point at which they are consumed. The second one is the 'origin principle', by which taxes are imposed at the source from which the goods are produced.

Although there are particular circumstances under which these principles are equivalent (Shibata, 1967; Whalley, 1979; Berglas, 1981), it is now clear that no general arguments emerge in favor of one or the other regime (Lockwood, 1993, 2001; Keen and Lahiri, 1998). On the one hand, the destination principle is difficult to manage in the Single Market because of the lack of barrier controls. On the other hand, under the origin principle, the theoretical literature highlights a sub-efficient process of downward tax competition which results in too low rates (Mintz and Tulkens, 1986; Crombrugghe and Tulkens, 1990; Kanbur and Keen, 1993; Haufler, 1994, 1998; Nielsen, 2001). These considerations may explain why the current EU 'transitional VAT System' actually maintains both modes of competition. It is indeed origin-based for sales to final consumers and for most service, and destination-based for operations between taxable persons and firms.

The present paper considers a stylized two-country model of commodity 
tax competition with a continuum of taxable commodities with domestic and foreign varieties, but only one available tax rate in each country, in addition to the zero-rate. There is no intermediate inputs, so that the tax system can be thought of as VAT, or more generally any kind of indirect tax system where there are a few rates of tax, e.g. the sales tax. We compare the optimal fiscal rule, which maximizes the joint welfare of countries, with equilibrium fiscal

rules in either mode of competition. In the presence of a restricted number of tax rates, competition partly falls back onto the tax base, providing countries an incentive to narrow their tax base and set higher rates. We show that, under the origin principle, the tax base (though not the tax rate) is narrower than the optimal one. Under this mode, if home and foreign goods of some variety are high substitutes, then they will be tax-free in equilibrium, whereas they should be taxed. Under the destination principle, the equilibrium rule is optimal.

We proceed as follows. Section 2 describes the economic framework, and defines the optimal tax rule and the equilibrium tax rules under the destination and the origin principles. It is proven that the optimal tax rule is implemented under the destination principle. In order to examine how the equilibrium tax rule under the origin principle departs from the optimal one, Section 3 is specialized to the case where the elasticities of substitution between home and foreign goods differ across varieties; for instance, home and foreign 'Public Transport' are lower substitutes than home and foreign 'Clothing'. In this case, the optimal tax base comprises all commodities, and it is larger than the equilibrium base. Section 4 considers two extensions. First it shows that, under the origin principle, any reform which imposes a larger base is Paretoimproving. Second, it provides a characterization of the equilibrium tax rule in the more general configuration where goods differ according to both elasticity of substitution and price elasticity.

\section{Framework}

This section describes the economic environment under scrutiny, and compares the optimal fiscal rule, i.e., the level of this rate and the set of taxed commodities which maximize the joint welfare of both countries, with those arising from tax competition under the destination and the origin principles. 


\subsection{Household problem}

Countries are labeled 'home' $(h)$ and 'abroad' $(A)$. Throughout the paper, a lower case letter applies to goods produced domestically while an upper case applies to goods produced in the foreign country. We focus on the efficiency viewpoint. Each country is therefore populated by one single representative household. The preferences of household $i(i=h, A)$ are represented by

$$
\int_{g \in G} u_{i}^{g}\left(x_{i}^{g}, X_{i}^{g}\right) d g-l_{i}
$$

where $x_{i}^{g}$ (resp. $X_{i}^{g}$ ) denotes the quantity of good $g$ consumed by household $i(i=h, A)$ and produced by country $h$ (resp. $A$ ), and $l_{i}$ represents the labor supply of household $i$. In (1), each variety $g, g \in G$, stands for some category of goods, e.g., bread, cars, pork meat, or blue trousers of some given size. Goods comprised in variety $g$ enter the preferences of household $i$ through the function $u_{i}^{g}(\cdot)$, assumed to be increasing and concave with respect to its arguments. Such goods may not be perfect substitutes because of differences in packaging, perceived qualities or poorer information about foreign goods.

We assume that both households have identical preferences, in the sense that $u_{h}^{g}(X, x)=u_{A}^{g}(x, X)$ for all $(x, X)$. The individual budget constraint writes

$$
\int_{g \in G}\left(q_{i}^{g} x_{i}^{g}+Q_{i}^{g} X_{i}^{g}\right) d g \leq l_{i}, \quad i=h, A
$$

where $q_{i}^{g}$ (resp. $Q_{i}^{g}$ ) is the price of good $g$ when consumed by household $i$ and produced by country $h$ (resp. $A$ ). The producer prices are normalized to 1 , so that $q_{i}^{g}=1+t_{i}^{g}$ and $Q_{i}^{g}=1+T_{i}^{g}$ where $t_{i}^{g}$ and $T_{i}^{g}$ are the rates applying to $g$.

The problem of household $i$ is to maximize (1) subject to (2). The separability assumptions embedded in (1) imply that the demand functions for goods of variety $g$ can be written $x_{i}^{g}=x_{i}^{g}\left(t_{i}^{g}, T_{i}^{g}\right)$ and $X_{i}^{g}=X_{i}^{g}\left(t_{i}^{g}, T_{i}^{g}\right)$, with a slight abuse of notation. The corresponding indirect utility is

$$
V_{i}=\int_{g \in G} v_{i}^{g}\left(t_{i}^{g}, T_{i}^{g}\right) d g,
$$

where $v_{i}^{g}\left(t_{i}^{g}, T_{i}^{g}\right)=u_{i}^{g}\left(x_{i}^{g}\left(t_{i}^{g}, T_{i}^{g}\right), X_{i}^{g}\left(t_{i}^{g}, T_{i}^{g}\right)\right)-q_{i}^{g} x_{i}^{g}\left(t_{i}^{g}, T_{i}^{g}\right)-Q_{i}^{g} X_{i}^{g}\left(t_{i}^{g}, T_{i}^{g}\right)$ is the individual contribution of variety $g$ to $i$ 's welfare. 


\subsection{Optimal fiscal rule}

The optimal fiscal rule maximizes the joint welfare $V_{h}+V_{A}$, with $t^{g}=T^{g}$ because of identical preferences, subject to the constraint that a given amount $R>0$ of tax is collected in each country,

$$
\int_{g \in G} t^{g}\left(x_{i}^{g}\left(t^{g}, t^{g}\right)+X_{i}^{g}\left(t^{g}, t^{g}\right)\right) d g \geq R .
$$

Since $x_{h}^{g}\left(t^{g}, t^{g}\right)=X_{A}^{g}\left(t^{g}, t^{g}\right)$ and $x_{A}^{g}\left(t^{g}, t^{g}\right)=X_{h}^{g}\left(t^{g}, t^{g}\right)$, both contributions $v_{h}^{g}\left(t^{g}, t^{g}\right)$ and $v_{A}^{g}\left(t^{g}, t^{g}\right)$ are equal for any $t^{g}$. Hence the optimal fiscal rule maximizes the Lagrangean

$$
2 \int_{g \in G} \mathcal{L}^{g}\left(t^{g}, t^{g}, \lambda\right) d g-2 \lambda R,
$$

where $\lambda$ is the marginal cost of public funds, and

$$
\mathcal{L}^{g}\left(t^{g}, t^{g}, \lambda\right)=v_{i}^{g}\left(t^{g}, t^{g}\right)+\lambda t^{g}\left(x_{i}^{g}\left(t^{g}, t^{g}\right)+X_{i}^{g}\left(t^{g}, t^{g}\right)\right)
$$

for $i=h, A$.

If $g$ could be taxed freely, then the optimal tax rate $t^{g}$ would maximize $\mathcal{L}^{g}$ for any $g$. These optimal tax rates would obey a version of Ramsey's rule, and so they would typically differ across varieties.

Here, however, we further require that only one positive rate is available, in addition to the zero-rate. Namely, we impose that $t^{g}=t>0$ if variety $g$ belongs to the tax base, and $t^{g}=0$ otherwise. With this additional constraint, the optimal base $b^{*}$ comprises every variety $g$ such that

$$
\mathcal{L}^{g}\left(t^{*}, t^{*}, \lambda^{*}\right)>\mathcal{L}^{g}\left(0,0, \lambda^{*}\right) .
$$

In (7), the optimal rate $t^{*}$ and the corresponding marginal social cost of public funds $\lambda^{*}$ satisfy the first order condition

$$
\frac{d}{d t} \int_{g \in b^{*}} \mathcal{L}^{g}\left(t^{*}, t^{*}, \lambda^{*}\right) d g=0
$$

and the budget constraint (4) at equality. 


\subsection{Tax competition}

We now turn to the case where $h$ and $A$ simultaneously choose their tax rules under competition.

Assume first that the origin principle applies. Then, the tax rate bearing on any good is the one of the country where this good has been produced, i.e. $t_{h}^{g}=t_{A}^{g}=t^{g}$ and $T_{h}^{g}=T_{A}^{g}=T^{g}$. Adopting country $h$ 's viewpoint, Nash behavior implies that $h$ takes $A$ 's tax rule $\left(T^{g} ; g \in G\right)$ as given and chooses $\left(t^{g} ; g \in G\right)$ which maximizes the indirect utility of household $h$,

$$
\int_{g \in G} v_{h}^{g}\left(t^{g}, T^{g}\right) d g
$$

subject to the constraints that the collected tax is at least $R$,

$$
\int_{g \in G} t^{g}\left(x_{h}^{g}\left(t^{g}, T^{g}\right)+X_{A}^{g}\left(t^{g}, T^{g}\right)\right) d g \geq R,
$$

and that only one tax rate can be used, that is, $t^{g}=t$ if $g$ belongs to $h$ 's tax base $b$, and $t^{g}=0$ otherwise.

The corresponding Lagrangean function writes

$$
\int_{g \in G} \mathcal{L}_{h, \mathrm{or}}^{g}\left(t^{g}, T^{g}, \lambda_{h}\right) d g-\lambda_{h} R
$$

where

$$
\mathcal{L}_{h, \text { or }}^{g}\left(t^{g}, T^{g}, \lambda_{h}\right)=v_{h}^{g}\left(t^{g}, T^{g}\right)+\lambda_{h} t^{g}\left(x_{h}^{g}\left(t^{g}, T^{g}\right)+X_{A}^{g}\left(t^{g}, T^{g}\right)\right),
$$

and $\lambda_{h}$ is the Lagrange multiplier associated to the budget constraint (9).

Therefore, $h$ should tax the goods of variety $g$ produced domestically at rate $t^{g}=t>0$ if and only if

$$
\mathcal{L}_{h, \text { or }}^{g}\left(t, T^{g}, \lambda_{h}\right)>\mathcal{L}_{h, \text { or }}^{g}\left(0, T^{g}, \lambda_{h}\right) .
$$

Given $A$ 's tax rule $\left(T^{g} ; g \in G\right)$, the domestic tax base $b$, the domestic tax rate $t$, and the multiplier $\lambda_{h}$ are defined by (11), the budget constraint (9) at equality, and the first order condition

$$
\frac{\partial}{\partial t^{g}} \int_{g \in b} \mathcal{L}_{h, \mathrm{or}}^{g}\left(t, T^{g}, \lambda_{h}\right) d g=0 .
$$


Equations (9) at equality, (11) and (12) define $h$ 's tax rule $(t, b)$ which is the best-response to any given rule $(T, B)$ in country $A$. The best-response $(T, B)$ of $A$ to the tax rule chosen by $h$ is defined similarly.

In a symmetric equilibrium, $t=T, b=B$ and $\lambda_{h}=\lambda_{A}=\lambda$. In this equilibrium, in each country, either the domestic and the foreign components of variety $g$ are taxed, or they are both exempted. Hence, a symmetric Nash equilibrium under the origin principle $\left(t_{\mathrm{or}}, b_{\mathrm{or}}, \lambda_{\mathrm{or}}\right)$ satisfies

$$
\begin{aligned}
& \mathcal{L}_{i, \text { or }}^{g}\left(t_{\text {or }}, t_{\text {or }}, \lambda_{\text {or }}\right)>\mathcal{L}_{i, \text { or }}^{g}\left(0, t_{\text {or }}, \lambda_{\text {or }}\right), \quad \text { for } g \in b_{\text {or }}, \\
& \mathcal{L}_{i, \text { or }}^{g}\left(0,0, \lambda_{\text {or }}\right) \geq \mathcal{L}_{i, \text { or }}^{g}\left(t_{\text {or }}, 0, \lambda_{\text {or }}\right), \quad \text { for } g \in G \backslash b_{\text {or }} .
\end{aligned}
$$

for $i=h, A$.

We are now in a position to assess optimality properties of the fiscal rule under the origin principle. Since both representative households are identical, we have $\mathcal{L}_{i, \text { or }}^{g}\left(t^{g}, t^{g}, \lambda\right)=\mathcal{L}^{g}\left(t^{g}, t^{g}, \lambda\right)$, where $\mathcal{L}^{g}$ is defined by (6). However, as is clear from (6) and $(10), \mathcal{L}_{i, \text { or }}^{g}(0, t, \lambda)$ and $\mathcal{L}_{i, \text { or }}^{g}(t, 0, \lambda)$ respectively differ from $\mathcal{L}^{g}(0, t, \lambda)$ and $\mathcal{L}^{g}(t, 0, \lambda)$. Therefore, there is no reason why the base $b_{\text {or }}$ under the origin principle should coincide with the optimal one, $b^{*}$. This implies in turn that, under this principle of taxation, the equilibrium tax rate $t_{\text {or }}$ and the associated marginal social cost of public funds $\lambda_{\text {or }}$ will not be set optimally.

By contrast, under the destination principle, the equilibrium is socially optimal. Under this principle, each country chooses the rate of tax applying to every good consumed at home, i.e. $t_{i}^{g}=T_{i}^{g}=t^{g}$ for every $g$. Hence, country $i$ now maximizes

$$
\int_{g \in G} v_{i}^{g}\left(t^{g}, t^{g}\right) d g
$$

under the budget constraint

$$
\int_{g \in G} t^{g}\left(x_{i}^{g}\left(t^{g}, t^{g}\right)+X_{i}^{g}\left(t^{g}, t^{g}\right)\right) d g \geq R .
$$

The Lagrangean of this problem coincides with $\mathcal{L}^{g}$, up to a (positive) scalar factor, as (5) and (6) show. This proves the statement that the equilibrium rule and the optimal one coincide. 
It follows that:

Proposition 1. Assume that there is only one positive tax rate, in addition to the zero-rate. Then, the optimal tax rule, i.e., the rate and the base which maximize the joint welfare of both countries, coincides with the one that is chosen under the destination principle. This rule differs, however, from the one that is chosen under the origin principle.

The intuition behind Proposition 1 is simple. As (15) and (16) highlight, domestic welfare under the destination principle neither depends on the foreign tax rate nor the foreign base. As a result, all possible pressures from fiscal competition do vanish.

Under the origin principle, this is no longer the case since the foreign tax rate influences the price of varieties consumed domestically. Nevertheless, at this level of generality, it seems difficult to assess more precisely how both fiscal rules differ. It might be that too many commodities are taxed in equilibrium. It might as well be that the equilibrium rate is too high. The next section provides insights into this issue by focusing attention on the mobility of taxable commodities.

\section{International mobility}

It is often claimed that substitution between domestic and foreign goods plays a crucial role in the shape of the fiscal base. In order to discuss this role, we set

$$
u_{i}^{g}\left(x_{i}, X_{i}\right)=\frac{1}{\rho(g)} \ln \left(x_{i}^{\rho(g)}+X_{i}^{\rho(g)}\right) .
$$

Variety $g$ is now indexed by the elasticity of substitution $\sigma(g)$ between foreign and domestic goods, with $\rho(g)=1-1 / \sigma(g), \sigma(g) \geq 0$. In general, the elasticity of substitution $\sigma(g)$ between home and foreign goods of variety $g$ varies across varieties. This parameter can be thought of as a measure of 'international mobility': the sub-utility $u_{i}^{g}$ approaches a Leontief when $\sigma(g) \rightarrow 0$, a CobbDouglas when $\sigma(g) \rightarrow 1$, and becomes linear when $\sigma(g) \rightarrow \infty$. Thus, the greater $\sigma(g)$ is, the more domestic and foreign goods which compose variety $g$ are close substitutes. 
Since complementarity between goods of the same variety is not relevant, we shall restrict our study to $\sigma(g) \geq 1$. When $\sigma(g)=1$, the domestic (resp. foreign) demand addressed to domestic (resp. foreign) goods of variety $g$ only relies on the domestic price $q^{g}=1+t^{g}$ (resp. $\left.Q^{g}=1+T^{g}\right)$; this seems to be more suitable for items such as 'Public Transport'. As the elasticity of substitution $\sigma(g)$ rises, domestic and foreign goods of variety $g$ become more sensible to the difference between $q^{g}$ and $Q^{g}$.

In (17), utility is logarithmic with respect to varieties. It follows that a comprehensive base should be socially desirable. Indeed, (7) rewrites

$$
\ln \left(1+t^{*}\right)<\lambda^{*} \frac{t^{*}}{1+t^{*}}
$$

Since this inequality does not depend on $\sigma(g)$, all commodities should be taxed at the social optimum.

We have consequently shown:

Proposition 2. If only one tax rate can be used, in addition to the zero-rate, then all commodities should be taxed at social optimum.

It is commonly argued that fiscal competition under the origin principle does result in too low rates. This is not the case here.

With the specification (17), it is readily verified that the contribution $\mathcal{L}_{h, \text { or }}^{g}\left(t^{g}, T^{g}, \lambda\right)$ of variety $g$ to welfare of country $h$ writes

$$
\frac{1}{\sigma(g)-1} \ln \left(\left(q^{g}\right)^{1-\sigma(g)}+\left(Q^{g}\right)^{1-\sigma(g)}\right)-1+2 \lambda_{i} \frac{q^{g}-1}{q^{g}} \frac{\left(q^{g}\right)^{1-\sigma(g)}}{\left(q^{g}\right)^{1-\sigma(g)}+\left(Q^{g}\right)^{1-\sigma(g)}} .
$$

The contribution $\mathcal{L}_{A, \text { or }}^{g}$ is obtained by switching $q^{g}=1+t^{g}$ and $Q^{g}=1+T^{g}$ in the above expression. Appealing to (13), a variety $g$ must be taxed in a symmetric Nash equilibrium under the origin principle when $\mathcal{L}_{i, \text { or }}^{g}(t, t, \lambda)>$ $\mathcal{L}_{i, \text { or }}^{g}(0, t, \lambda)$, for $i=h, A$, which is here equivalent to

$$
\lambda \frac{t}{1+t}>F^{T}(\sigma(g)) \equiv \frac{1}{\sigma(g)-1} \ln \left(\frac{1+(1+t)^{\sigma(g)-1}}{2}\right) .
$$


Similarly, using (14), a variety $g$ must be exempted if and only if $\mathcal{L}_{i \text {,or }}^{g}(t, 0, \lambda) \leq$ $\mathcal{L}_{i, \mathrm{or}}^{g}(0,0, \lambda)$, for $i=h, A$, that is

$$
\lambda \frac{t}{1+t} \leq F^{G \backslash T}(\sigma(g)) \equiv \frac{1+(1+t)^{\sigma(g)-1}}{2(1-\sigma(g))} \ln \frac{1+(1+t)^{1-\sigma(g)}}{2} .
$$

Relevant properties of $F^{T}(\sigma)$ and $F^{G \backslash T}(\sigma)$ are listed in Lemma 1.

Lemma 1. For $\sigma>1, F^{T}(\sigma)$ and $F^{G \backslash T}(\sigma)$ are increasing with respect to $\sigma$, $F^{T}(\sigma)<F^{G \backslash T}(\sigma)$, and

$$
\lim _{\sigma \rightarrow 1^{+}} F^{T}(\sigma)=\lim _{\sigma \rightarrow 1^{+}} F^{G \backslash T}(\sigma)=\frac{1}{2} \ln (1+t) .
$$

Proof. Let $x=(1+t)^{\sigma-1}>1$. Then,

$$
\frac{d F^{T}(\sigma)}{d \sigma}>0 \Leftrightarrow G(x)=\ln \left(\frac{1+x}{2}\right)-\frac{x \ln x}{1+x}<0 .
$$

Since $G(1)=0$ and $G^{\prime}(x)<0$ for $x>1$, we have $G(x)<0$ for $x>1$. This shows that $F^{T}(\sigma)$ is increasing with $\sigma$ for any $\sigma>1$. Moreover,

$$
\frac{d F^{G \backslash T}(\sigma)}{d \sigma}>0 \Leftrightarrow H(x)=(x+1-x \ln x) \ln \left(\frac{1+x}{2 x}\right)+\ln x>0 .
$$

It is easy to check that, for $x>1, H^{\prime}(x)$ has the same sign as

$$
I(x)=\frac{1}{1+x}-\ln \left(\frac{1+x}{2 x}\right)
$$

The monotonicity property of $F^{G \backslash T}(\sigma)$ then follows from the fact that $I(x)<$ 0 , for $x>1$ (since $I(\cdot)$ is increasing for $x>1$ and $I(\infty)=0$ ). Finally, remark that

$$
F^{T}(\sigma)-F^{G \backslash T}(\sigma)<0 \Leftrightarrow J(x)=\ln \left(\frac{1+x}{2}\right)+\frac{1+x}{2} \ln \frac{1+x}{2 x}<0,
$$

which is true since $J(1)=J^{\prime}(1)=0$, and $J^{\prime \prime}(x)<0$ for $x>1$, so that $J(x)<0$ for $x>1$. Appealing to L'Hospital rule completes the proof. 
This result allows us to characterize the equilibrium fiscal base under the origin principle. As is illustrated in Figure 1, there exist two thresholds $\bar{\sigma}$ and $\hat{\sigma}<\bar{\sigma}$. If, in any given variety $g$ such that $\sigma(g)<\hat{\sigma}$, goods produced abroad are taxed, then domestic goods should be taxed; if, on the contrary, foreign goods in this variety are exempted, then domestic goods should be taxed at home. Therefore, in a symmetric equilibrium, all components of this variety will necessarily be taxed in both countries. By the same argument, any variety $\sigma(g) \geq \bar{\sigma}$ will be tax-free in both countries, while varieties $\hat{\sigma} \leq \sigma(g)<\bar{\sigma}$ can be either taxed or exempted in both countries.

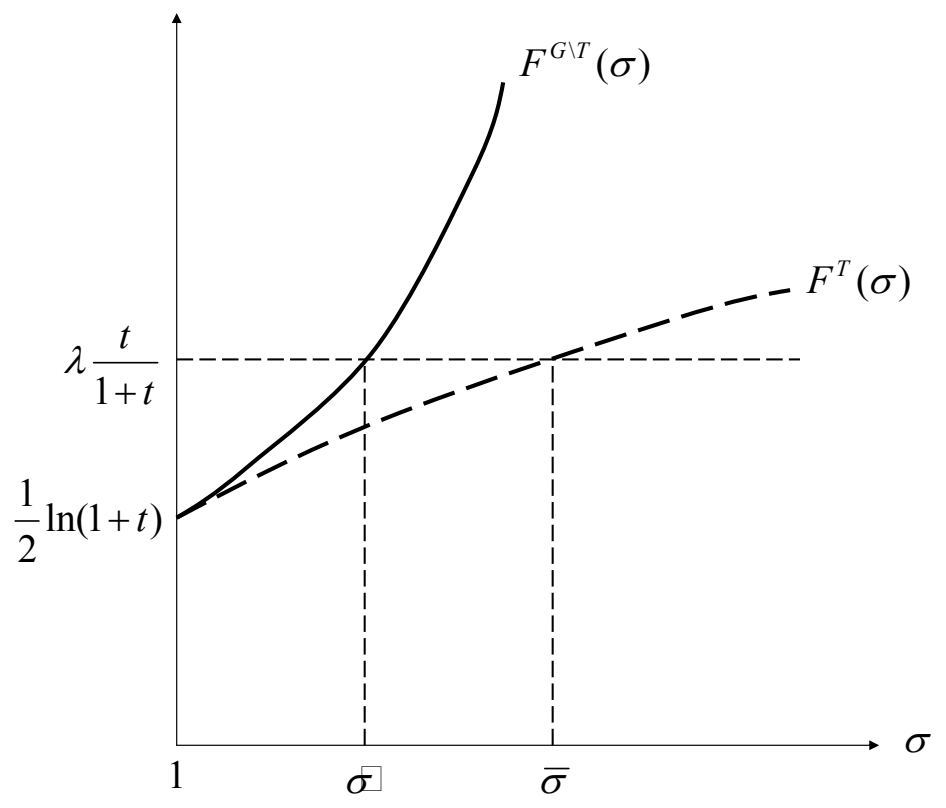

Figure 1: Equilibrium fiscal base

Proposition 3. Under the origin principle, in any symmetric equilibrium, there exist two threshold elasticities of substitution $\hat{\sigma}$ and $\bar{\sigma}$, with $\hat{\sigma}<\bar{\sigma}$, such that all varieties $g$ with $\sigma(g)<\hat{\sigma}$ are taxed, and all varieties $g$ with $\sigma(g) \geq \bar{\sigma}$ are exempted.

The fiscal base under the origin principle does not comprise all varieties. It is too narrow with respect to the optimal fiscal base, and consequently the equilibrium tax rate is too high. 


\section{Two extensions}

\subsection{A tax reform perspective}

There is a related literature on Pareto improving tax harmonization under the destination principle (Keen, 1987) or the origin principle (Lopez-Garcia, 1996, 1998). Its purpose is to examine, from a tax reform perspective, whether

small adjustments of tax rates toward a common structure may lead to a Pareto improvement. There are actually constraints on the levels of VAT rates in the EU. For instance, the standard VAT rate must be at least $15 \%$ and, by political commitment, it must be less than 25\%. Though this may justify the examination of whether a form of convergence across VAT rates should be implemented, such constraints clearly do not prevent significant divergences among the rates of VAT.

The main legal restriction in the EU imposes on Member States the use of a small number of different tax rates. In this circumstance, Proposition 2 suggests that the optimal fiscal base is likely to be large. Since, by Proposition 3 , the equilibrium rate of tax is too high under the origin principle, it seems natural to examine whether a small reduction of the standard rate may increase welfare in both countries.

To discuss this point, assume that $h$ and $A$ are initially in a symmetric Nash equilibrium under the origin principle. They have the same tax rate and the same tax base. For notational convenience, let varieties be ranked by increasing order of substitution elasticities, i.e. $\sigma(g)<\sigma\left(g^{\prime}\right)$ for $g<g^{\prime}$. Let also $\bar{g}$ be the threshold variety such that the initial tax base comprises any $g$ with $\sigma(g) \leq \sigma(\bar{g})$. By Proposition 3, it must be that $\hat{\sigma} \leq \sigma(\bar{g})<\bar{\sigma}$.

If the tax rate level is modified by a small amount $d t$ in both countries, the budget constraint (9) implies that, in order to collect the required amount of tax, the base must be adjusted by $d \bar{g}$ such that

$$
t\left(x_{i}^{\bar{g}}(t, t)+X_{j}^{\bar{g}}(t, t)\right) d \bar{g}+\frac{\partial}{\partial t}\left[t \int_{g \leq \bar{g}}\left(x_{i}^{g}(t, t)+X_{j}^{g}(t, t)\right) d g\right] d t=0
$$

for $i=h, A$ and $j \neq i$. In the 'non-crazy case' (Lipsey and Lancaster, 1956), a decrease in tax rate $(d t<0)$ leads to a decrease in the amount of collected tax. Therefore, the fiscal base must be enlarged $(d \bar{g}>0)$ and thus becomes closer to the optimal one. 
The initial level of welfare

$$
V=\int_{g \leq \bar{g}} v^{g}(t, t) d g+\int_{g \geq \bar{g}} v^{g}(0,0) d g
$$

is identical in both countries. As a result, the reform $(d t, d \bar{g})$ implies the same welfare change $d V$ in both countries, with

$$
d V=\left(\int_{0}^{t} \frac{\partial}{\partial \tau} v^{\bar{g}}(\tau, \tau) d \tau\right) d \bar{g}+\left(\int_{g \leq \bar{g}} \frac{\partial}{\partial t} v^{g}(t, t) d g\right) d t .
$$

Using Roy's identity, the budget constraint (19), and the fact that $x_{h}^{g}(t, t)=$ $X_{h}^{g}(t, t)=x_{A}^{g}(t, t)=X_{A}^{g}(t, t) \equiv x^{g}(t, t)$ in the initial situation, we obtain

$$
\frac{1}{2} \frac{d V}{d t}=\frac{\partial}{\partial t}\left(t \int_{g \leq \bar{g}} x^{g}(t, t) d g\right) \int_{0}^{t} \frac{x^{\bar{g}}(\tau, \tau)}{t x^{\bar{g}}(t, t)} d \tau-\int_{g \leq \bar{g}} x^{g}(t, t) d g .
$$

Hence, for $d t<0$,

$$
d V>0 \Leftrightarrow \frac{\partial}{\partial t}\left(t \int_{g \leq \bar{g}} x^{g}(t, t) d g\right) \int_{0}^{t} \frac{x^{\bar{g}}(\tau, \tau)}{t x^{\bar{g}}(t, t)} d \tau<\int_{g \leq \bar{g}} x^{g}(t, t) d g .
$$

This inequality will be satisfied if the initial base, which appears in the RHS, is initially large enough, while the amount of collected tax is not too sensitive to a change in tax rate.

With the specification (17), we have $x^{g}(t, t)=1 / 2(1+t)$ for all $g \leq \bar{g}$ in the initial symmetric equilibrium. Thus, $d V>0 \Leftrightarrow \ln (1+t)<t$. Since this inequality is always satisfied (for $t>0$ initially), any reform that imposes a small reduction in the tax rate in both countries, accompanied with an adjustment of the fiscal base such that the collected tax remains unchanged, is Pareto-improving.

The argument shows that the result does not rely on the initial position of the economy at the outset of the reform. It only makes use of the fact that the government budget constraints are initially binding. This property suggests that a dynamic process of tax reforms should impose a reduction in the level of the tax rate until the optimal base is achieved. 


\subsection{Price elasticities}

In a closed economy, the Ramsey's rule closely relies on domestic price elasticities. In order to take this point into account, let (17) be

$$
u_{i}^{g}\left(x_{i}, X_{i}\right)=\frac{\varepsilon(g)}{\varepsilon(g)-1}\left(x_{i}^{\rho(g)}+X_{i}^{\rho(g)}\right)^{\frac{\varepsilon(g)-1}{\varepsilon(g)} \frac{\sigma(g)}{\sigma(g)-1}} .
$$

Variety $g$ is characterized by its own price elasticity $\varepsilon(g)$ and the elasticity of substitution $\sigma(g)$ across goods in this variety. Then the equilibrium base under

the origin principle comprises variety $g$ only if $\mathcal{L}_{i, \text { or }}^{g}(t, t, \lambda)>\mathcal{L}_{i, \text { or }}^{g}(0, t, \lambda)$, for $i=h, A$, which is equivalent to $\lambda t /(1+t)>F^{T}(\varepsilon(g), \sigma(g))$, with

$$
F^{T}(\varepsilon, \sigma)=\frac{1}{\varepsilon-1}\left(\left(\frac{q^{\sigma-1}+1}{2}\right)^{\frac{\varepsilon-1}{\sigma-1}}-1\right) .
$$

Similarly, variety $g$ is exempted only if $\mathcal{L}_{i, \text { or }}^{g}(0,0, \lambda) \geq \mathcal{L}_{i \text { or }}^{g}(t, 0, \lambda)$, for $i=h, A$, or equivalently $\lambda t /(1+t) \leq F^{G \backslash T}(\varepsilon(g), \sigma(g))$, where

$$
F^{G \backslash T}(\varepsilon, \sigma)=\frac{1}{\varepsilon-1} \frac{q^{\sigma-1}+1}{2}\left(\left(\frac{2}{q^{1-\sigma}+1}\right)^{\frac{\varepsilon-1}{\sigma-1}}-1\right) .
$$

One can check that $F^{T}(\varepsilon, \sigma)$ and $F^{G \backslash T}(\varepsilon, \sigma)$ increase with $\varepsilon$. Hence, as depicted in Figure 2, varieties with high (resp. low) price elasticities are exempted (resp. taxed) in equilibrium.

The threshold elasticities of substitution $\hat{\sigma}$ and $\bar{\sigma}$ characterized in Proposition 3 are obtained when the price elasticity $\varepsilon$ equals 1 . More generally, the dashed curve separates the plane in two regions: region $T T$ comprises varieties $(\varepsilon(g), \sigma(g))$ for which domestic goods are taxed when foreign goods are taxed, i.e. satisfying inequality (20), while region $E T$ comprises varieties $(\varepsilon(g), \sigma(g))$ for which domestic goods are tax-free when foreign goods are taxed. Similarly, the solid bold curve separates region $E E$, where inequality (21) is satisfied, from region $E T$. Therefore, in equilibrium, varieties whose representative point stands below the solid bold curve (in $T T \cap T E$ ) are taxed and those above the dashed curve (in $E T \cap E E$ ) are exempted. 


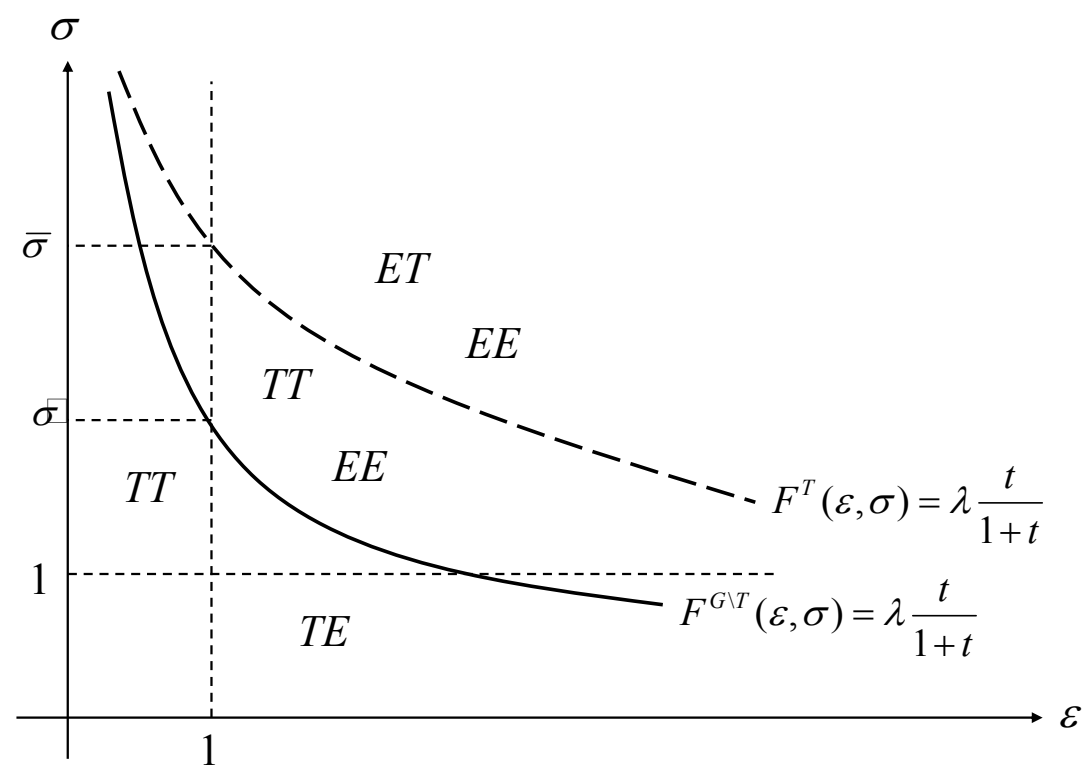

Figure 2: Equilibrium fiscal base with heterogenous price elasticities

\section{References}

[1] Berglas, E., 1981, Harmonization of commodity taxes: destination, origin and restricted origin principles, Journal of Public Economics 16, 377-87.

[2] Crombrugghe, A., and H. Tulkens, 1990, On Pareto improving commodity tax changes under fiscal competition, Journal of Public Economics 41(3), 335-350.

[3] Haufler, A., 1994, Unilateral tax reform under the restricted origin principle, European Journal of Political Economy 10(3), 511-527.

[4] Haufler, A., 1998, Asymmetric commodity tax competition-comment on de Crombrugghe and Tulkens, Journal of Public Economics 67, 135-144.

[5] Kanbur, R. and M. Keen, 1993, Jeux sans frontières: tax competition and tax coordination when countries differ in size, American Economic Review 63, 877-892. 
[6] Keen, M., 1987, Welfare effects of commodity tax harmonization, Journal of Public Economics 33, 107-114.

[7] Keen, M. and S. Lahiri, 1998, The comparison between destination and origin principles under imperfect competition, Journal of Public Economics 45, 323-350.

[8] Lipsey, R.G. and K. Lancaster, 1956, The general theory of second best, Review of Economic Studies, 24, 11-32.

[9] Lockwood, B., 1993, Commodity tax competition under destination and origin principles, Journal of Public Economics 52(2), 141-162.

[10] Lockwood, B., 2001, Tax competition and tax coordination under destination and origin principles: a synthesis, Journal of Public Economics 81(2), 279-319.

[11] Lopez-Garcia, M.A., 1996, The origin principle and the welfare gains from indirect tax harmonization, International Tax and Public Finance 3, 8393.

[12] Lopez-Garcia, M.A., 1998, On welfare and revenue effects of indirect tax harmonization, Economics Letters 60, 185-193.

[13] Mintz, J., and H. Tulkens, 1986, Commodity tax competition between member states of a federation: equilibrium and efficiency, Journal of Public Economics 29, 133-172.

[14] Nielsen, S.B., 2001, A simple model of commodity taxation and crossborder shopping, Scandinavian Journal of Economics 103(4), 599-623.

[15] Shibata, H., 1967, The theory of economic unions, in C. S. Shoup (ed.), Fiscal Harmonisation in Common Markets, Columbia University Press.

[16] Whalley, J., 1979, Uniform domestic tax rates, trade distorsions and economic integration, Journal of Public Economics 11, 213-221. 